This PDF is a selection from a published volume from the National Bureau of Economic Research

Volume Title: Measuring the Subjective Well-Being of Nations: National Accounts of Time Use and Well-Being

Volume Author/Editor: Alan B. Krueger, editor

Volume Publisher: University of Chicago Press

Volume ISBN: 0-226-45456-8

Volume URL: http://www.nber.org/books/krue08-1

Conference Date: December 7-8, 2007

Publication Date: October 2009

Title: Measuring National Well-Being

Author: David M. Cutler

URL: http://www.nber.org/chapters/c5055 


\title{
Measuring National Well-Being
}

\author{
David M. Cutler
}

The chapter by Alan Krueger and colleagues (chapter 1, this volume) is an ambitious attempt to measure the well-being of the population. The chapter is nominally about how we spend our time, but it is really about how we live our lives. Are we better off than we used to be? That is the ultimate motivation for a set of time accounts.

There is much to discuss in the well-being chapter. I focus my comments on three areas.

The distinction between time accounting and well-being accounting What is missing conceptually in the U-index Possible answers to the puzzle of the United States and the French

\subsection{Time Accounts and Well-Being Accounts}

Krueger and colleagues place their analysis in the history of time accounting. But much of the genesis of their work is in the measurement of wellbeing. We care about what we do, after all, because we want to know what we get for our efforts. Market activity is only one measure of well-being; time allocation promises to open a window on the remainder.

I assume for my comments that our ultimate goal is to measure national well-being. I ask how well the U-index does in that regard.

A historical development shows some of the limitations. While Krueger and colleagues give many antecedents to their work, they miss one of the most important ones: Jeremy Bentham in the 1840s. Bentham is best known as the founder of utilitarian analysis. He also tried to quantify how

David M. Cutler is the Otto Eckstein Professor of Applied Economics at Harvard University and a research associate of the National Bureau of Economic Research. 
happy people were. Bentham laid out his felicity calculus in An Introduction to the Principles of Morals and Legislation, published in 1823. In that work, Bentham delineated fourteen simple pleasures and twelve simple pains (complex pleasures and pains involved combinations of the simple pleasures and pains). The list of pleasures and pains is detailed in table 3.1.

There is clearly some overlap between Bentham's pleasures and pains and those in Krueger et al. Pleasures of the sense are (somewhat) captured in the Krueger et al. analysis. Pleasures of expectation, relief, and those dependent on association are also captured to some extent. But many of the pleasures and pains are missing. Pleasures of wealth, skill, amity, a good name, piety, and benevolence are generally missing, for example.

A bit of inspection suggests the difference. The U-index proposed by Krueger and colleagues is about the process of consuming goods, not about the enjoyment of the actual consumption. Thus, time spent preparing a meal counts as valuable or not, but the quality of the meal is not valued. Similarly, work is counted as a disamenity, but the goods that the work buys are not included on the good side of the ledger.

This distinction between process measures and existential measures is key to resolving one of the major puzzles highlighted by the Krueger et al. work: why do Americans spend so much of their time - nearly 20 percentengaged in activities that they do not find pleasurable? Clearly, they do that so that they can afford other pleasures: better food and clothes, more gadgets, and so on. But those other pleasures are not counted as improving welfare. Thus, we appear more miserable than we are.

Existential happiness is not just about material goods consumption. Consider the example of a smoker who gives up smoking so that he can live a

Table 3.1 Jeremy Bentham's simple pleasures and pains

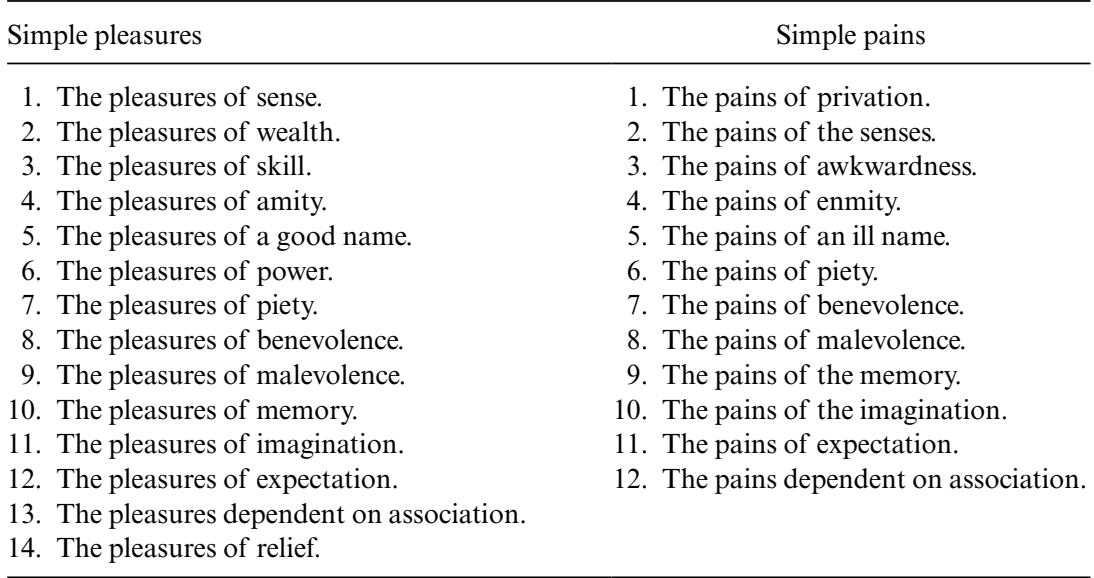

Source: Bentham (1823). 
longer, healthier life. The loss of pleasure from the foregone cigarettes will show up in lower happiness for some period of time. But the psychic enjoyment that comes with knowing that one has done the right thing will not.

Krueger and colleagues limit their analysis to time allocation, because they want to avoid these existential valuations. But that strikes me as too limiting. The major problem that needs to be addressed is how to measure the well-being of the population. Time allocation is most useful if it can contribute to that analysis.

\subsection{The Formation of the U-Index}

Let me leave aside the conceptual issues about well-being and turn to the formation of the U-index. How shall we measure the amount of time a person spends doing unpleasant activities? The index that Krueger and colleagues propose is generally reasonable, but I have a few amendments to offer.

One issue is the treatment of the family. Krueger and colleagues consider the unit to be the individual. But the family might be more appropriate. Consider the example of a wife who goes to work so that her husband does not have to work as much. The disamenity of working will be noted on the wife's account. The husband will have fewer hours of unhappiness, but still some. It may be that reported unhappiness is the same (equal hours increase for her as a reduction for him). Or perhaps more hours are worked in total (if the wage of the wife is not high), leading to an increase in U. But because the family made the decision to maximize joint welfare, the family is happier overall.

A second major conceptual issue on which I would like to see more work is the separability of the utility function. Krueger and colleagues note that their index only makes sense if utility is independent across activities. If utility is interdependent, the authors cannot analyze each activity separately. At some ultimate level, separability cannot be true. Consider health. At very low levels of health - for example, death or near death - there is no utility from any other activity. Thus, utility cannot be independent. A less extreme case might be work. If people do not work and thus have extremely low income, the unpleasantness associated with most any activity will be high. What is pleasurable about leisure if one has no money at all?

One way that Krueger and colleagues might examine this is by relating overall satisfaction to happiness in different domains, and interactions of domain-specific happiness. If the interactions are significantly related to overall health, that would suggest possible nonlinearities to examine.

I do not have the Krueger et al. data to do this, but I do have some information that can be brought to bear on this. Danny Blanchflower kindly made available to me data from the General Social Survey (GSS) from 1972 through 2006. In many years, the GSS asked people an overall level of hap- 
piness (not too happy, pretty happy, and very happy), and questions about their satisfaction with different aspects of their life: family, friends, health, job, and financial. Satisfaction is coded on a 1 to 7 basis: none; a little; some; a fair amount; quite a bit; a great deal; and a very great deal. I sample adults in all years who are asked overall happiness and the five domains of satisfaction. The sample is 19,029 people.

The first column of table 3.2 relates overall happiness to satisfaction in each of the five domains. Because happiness is an ordered variable with three responses, I use an ordered probit regression. To control for time trends, I also include year dummy variables (not reported). Satisfaction in each domain of life is associated with greater happiness. The largest coefficient is for financial satisfaction; job and family satisfaction are next, and health and friend satisfaction are least important.

The second column of the table includes those five satisfaction variables and two-way interactions between each of them - ten in total. While the standard errors on each interaction are large, the $\chi$-squared test rejects the null hypothesis that the interaction coefficients are all insignificant. Most of the interaction terms are positive; being more satisfied in one domain increases the impact of satisfaction in other domains on overall well-being. To the extent there is a hierarchy, satisfaction with family and friends is most basic. People who are not satisfied with family and friends find that satisfaction in other areas of life translates little into overall happiness.

There are clearly significant issues associated with the interpretation of happiness measures, which I do not discuss. Rather, I want to use take from these results that happiness in different domains is unlikely to be independent, and thus that unhappiness with time allocation is unlikely to be independent of what else a person is doing. Using the rich data in the surveys that Krueger and all collect, they could do a detailed analysis of how overall time allocation affects well-being.

\subsection{Cross-Country Comparisons}

I address the third part of my comments to the most interesting substantive finding in the Krueger et al. work - the fact that the French are so much happier than Americans. The reason for this is not hard to divine: the French work less than Americans. But why do Americans work so much? American workers are just as productive as French workers; thus, we could be as happy as the French are, by working less and enjoying leisure more. Why do we not do this?

One possibility is that Krueger et al. are wrong-we are not less happy than the French. It is true that the French spend less time at work, but our additional income buys us more material goods: bigger houses, more food, flat screen TVs, and the like. Since consumption values are not well captured by the index, it appears we are less happy, when in fact we are not. 
(1)

(2)

Satisfaction with

Family

Friends

Health

Job

Financial

Interactions between satisfaction

Family and friends

Family and health

Family and job

Family and financial

Friends and health

Friends and job

Friends and financial

Health and job

Health and financial

Job and financial

$N$

$\ln ($ Likelihood)
.201

(.007)

.105

(.008)

.125

(.007)

.264

(.011)

.337

(.012)

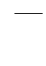

.124

$-.084$

(.079)

.016

(.067)

.064

(.099)

.059

(.109)

.008

(.005)

.008

(.005)

.002

(.009)

$-.004$

(.010)

.008

(.005)

.002

(.009)

.015

(.011)

$-.001$

(.008)

.004

(.009)

.031

(.015)

19,029

19,029

$-15,396.929$

Notes: Ordered probit model for "not too happy," "pretty happy," "happy." All regressions contain year dummy variables. Dashes indicate that the variable was not included in the regression model.

There is no perfect way to test this. One type of test is to see whether revealed preference is at all useful in predicting what people do. The most basic test of revealed preference is that people who like work less should work fewer hours. If this is true, it suggests that people are optimizing, and perhaps there is some truth in this explanation. If people who dislike work more work the same or additional hours, it suggest that people are in a suboptimal time allocation. 
One possible reason for this is my second theory about the continental differences in happiness: we think we know what will make us happy, but we are continually wrong. In this theory, Americans are led to believe that working long and hard is good, because it allows us money to live in the suburbs and raise our families. What we forget to take into account, though, is that living in the suburbs involves long commutes, and working more means more interaction with the boss. Something else is needed to close this theory; we do learn, after all, that work is stressful and commutes are unpleasant. But one could imagine a situation where people are deluded for a period of time, and thus we are less happy than people in other countries.

A final theory is that leisure is complementary across people, and thus that no single American could be happy if they chose the French lifestyle. Vacation might be more fun because everyone is on vacation; when others are at work, relaxation may be difficult.

The types of regressions I suggested previously might be used to test this. In particular, it suggests that work might be more satisfying when one has many close friends who work, or when friends and family work many hours. Krueger or others might test this.

\subsection{Conclusion}

Alan Krueger and colleagues have written a chapter designed to provoke. It certainly does that. I hope they will continue on the path, to pull together the well-being of the U.S. population. To do that, however, the analysis will need to expand beyond what we do and get into the issue of how well we like the results. The data and conceptual needs involved could be quite substantial.

\section{References}

Bentham, J. 1823. An introduction to the principles of morals and legislation. London: W. Pickering.

National Opinion Research Center (NORC). 1972-2006. General social survey. The University of Chicago. Available at: http://www.norc.org/GSS+Website/. 